\title{
Convalescent plasma treatment for SARS-CoV-2 infection: analysis of the first 436 donors in England, 22 April to 12 May 2020
}

Heli Harvala ${ }^{1}$, Jennifer Mehew ${ }^{2}$, Matthew L Robb ${ }^{2}$, Samreen ljaz ${ }^{3}$, Steven Dicks ${ }^{1,3}$, Monika Patel ${ }^{4}$, Nicholas Watkins ${ }^{5}$, Peter Simmonds ${ }^{6}$, Tim Brooks ${ }^{7}$, Rachel Johnson ${ }^{2}$, Robin Gopal ${ }^{4}$, David J Roberts ${ }^{8,9}$, Maria Zambon ${ }^{3}$, the NHS Blood and Transplant Convalescent Plasma Testing Group ${ }^{10}$

1. Microbiology Services, NHS Blood and Transplant, London, United Kingdom

2. Statistics and Clinical Studies, NHS Blood and Transplant, Bristol, United Kingdom

3. Virology Reference Department, National Infection Service, Public Health England, Colindale Avenue, London, United Kingdom

4. High Containment Microbiology, National Infection Service, Public Health England, Colindale Avenue, London, United Kingdom

5. NHS Blood and Transplant, Cambridge, United Kingdom

6. Nuffield Department of Medicine, University of Oxford, Oxford, United Kingdom

7. Rare \& Imported Pathogens Laboratory, Public Health England, Porton Down, United Kingdom

8. NHS Blood and Transplant, Oxford, John Radcliffe Hospital, Oxford, United Kingdom

9. Radcliffe Department of Medicine and BRC Haematology Theme, University of Oxford, John Radcliffe Hospital, Oxford, United Kingdom

10. The members of the NHS Blood and Transplant Convalescent Plasma Testing Group are listed below

Correspondence: Heli Harvala (heli.harvalasimmonds@nhsbt.nhs.uk)

Investigator group:

NHS Blood and Transplant Convalescent Plasma Testing Group: Stephen Thomas, Sheila MacLennan, Lise Estcourt, Su Brailsford, Hatice Baklan, Kate Tettmar, Jeremy Kellington, Joanne Sell, Gail Miflin

Citation style for this article:

Harvala Heli, Mehew Jennifer, Robb Matthew L, ljaz Samreen, Dicks Steven, Patel Monika, Watkins Nicholas, Simmonds Peter, Brooks Tim, Johnson Rachel , Gopal Robin, Roberts David J , Zambon Maria, the NHS Blood and Transplant Convalescent Plasma Testing Group . Convalescent plasma treatment for SARSCoV-2 infection: analysis of the first 436 donors in England, 22 April to 12 May 2020. Euro Surveill. 2020;25(28):pii=2001260. https://doi.org/10.2807/1560-7917. ES.2020.25.28.2001260

Serological reactivity was analysed in plasma from 436 individuals with a history of disease compatible with COVID-19, including 256 who had been laboratory-confirmed with SARS-CoV-2 infection. Over $99 \%$ of laboratory-confirmed cases developed a measurable antibody response $(254 / 256)$ and $88 \%$ harboured neutralising antibodies (226/256). Antibody levels declined over 3 months following diagnosis, emphasising the importance of the timing of convalescent plasma collections. Binding antibody measurements can inform selection of convalescent plasma donors with high neutralising antibody levels.

The emergence in China, at the end of 2019, of severe acute respiratory syndrome coronavirus 2 (SARSCoV-2), a virus causing coronavirus disease (COVID-19), was followed by a rapid spread of the virus, leading to the announcement of a COVID-19 pandemic on 11 March $2020[1,2]$. Without an effective treatment or a vaccine, convalescent plasma therapy has been recommended to tackle COVID-19 associated morbidity and mortality [3,4]. Neutralising antibodies to SARS-CoV-2 in plasma collected from recovered patients is likely to support such therapy [5-7]. The timing and nature of immune response associated with SARS-CoV-2 infection is variable in recovering individuals, although seroconversion is typically detectable 14 days post infection [8-11]. Furthermore, higher neutralising antibody levels have been measured in older individuals $[11,12]$ and those with more severe SARS-CoV-2 infections [10]. Here we analysed the performance of serological assays designed to detect antibodies against SARS-CoV-2 and assessed host factors associated with elevated neutralising antibody levels in order to improve donor selection.

\section{Collecting plasma samples}

In England, the National Health Service (NHS) Blood and Transplant is collecting convalescent plasma from individuals with confirmed or suspected SARS-CoV-2 infection at least 28 days after the resolution of their symptoms, and donations containing a minimum neutralising antibody titre of 1:100 are provided for clinical use $[13,14]$.

During the first weeks of convalescent plasma apheresis collections (22 April to 12 May), a total of 436 donations were obtained. Donors were aged between 17 and 65 years. Convalescent plasma was primarily collected from individuals for whom SARS-CoV-2 infection had been laboratory-confirmed by RT-PCR, but donations were also taken from individuals with self-reported 
Results of Euroimmun IgG ELISA, live virus lysate total IgG antibody ELISA, and microneutralisation test for neutralising antibody detection, on plasma samples of donors recovered from self-reported or laboratory-confirmed SARS-CoV-2 infections ( $\mathrm{n}=436$ plasma samples)

\begin{tabular}{|c|c|c|c|c|c|c|c|c|c|c|}
\hline \multirow[b]{2}{*}{ Samples } & \multirow{2}{*}{$\begin{array}{l}\text { Total } \\
\text { number }\end{array}$} & \multicolumn{3}{|c|}{ Euroimmun IgG ELISA } & \multicolumn{3}{|c|}{ Live virus lysate ELISA } & \multicolumn{3}{|c|}{ Neutralising antibody test } \\
\hline & & Reactive & $\begin{array}{l}\text { Non- } \\
\text { reactive }\end{array}$ & $\begin{array}{c}\% \\
\text { Reactive }\end{array}$ & Reactive & $\begin{array}{c}\text { Non- } \\
\text { reactive }\end{array}$ & $\begin{array}{c}\% \\
\text { Reactive }\end{array}$ & Detected & $\begin{array}{c}\text { Not } \\
\text { detected }\end{array}$ & \begin{tabular}{|l|}
$\%$ \\
Detected \\
\end{tabular} \\
\hline All samples & 436 & 346 & 90 & 79.4 & 379 & 57 & 86.9 & 331 & 105 & 75.9 \\
\hline \multicolumn{11}{|c|}{ Samples from confirmed cases } \\
\hline $\begin{array}{l}\begin{array}{l}\text { All with confirmed } \\
\text { diagnosis }\end{array} \\
\end{array}$ & 256 & 232 & 24 & 90.6 & 254 & 2 & 99.2 & 226 & 32 & 88.2 \\
\hline 30-40 days post diagnosis & 91 & 83 & 8 & 91.2 & 91 & 0 & 100 & 79 & 12 & 86.8 \\
\hline 40-50 days post diagnosis & 123 & 115 & 8 & 93.5 & 123 & 0 & 100 & 112 & 11 & 91.1 \\
\hline$>50$ days post diagnosis & 42 & 34 & 8 & 81.0 & 40 & 2 & 95.2 & 35 & 7 & 83.3 \\
\hline
\end{tabular}

SARS-CoV-2: severe acute respiratory syndrome coronavirus 2.

previous suspected infection. Based on the NHS Blood and Transplant donation and NHS Digital diagnostic record matching, 256 convalescent plasma donors were identified as having had a previous laboratoryconfirmed SARS-CoV-2 infection (256/436, 59\%). The diagnosis had been made between 31 and 60 days before the donation, and fewer than $10 \%$ were known to have been hospitalised $(22 / 256)$. Some of the remaining donors may also have had a laboratory-confirmed SARS-CoV-2 infection, but this could not be confirmed.

\section{Ethical statement}

Signed donor consent was obtained for the purposes of clinical audit, to assess and improve the service and for research, and specifically to improve our knowledge of the donor population.

\section{Detection of antibodies and sample processing}

All donations were tested for SARS-CoV-2 RNA by RT-PCR and antibodies. The presence of IgG antibodies in all plasma samples was assessed using a SARS-CoV-2 infected cell lysate ELISA assay and by Euroimmun ELISA (S1; PerkinElmer, London, United Kingdom), which uses the spike protein as antigen. Neutralising antibodies were detected using a microneutralisation assay as previously described [13]. Donations with a signal to cut-off $(\mathrm{S} / \mathrm{CO})$ ratio of 9.1 or higher in the Euroimmun assay were released for clinical use before microneutralisation assay results were available as this cut-off was previously shown to identify donations with a minimum neutralising antibody titre of 1:100 with a specificity of $100 \%$ [13].

\section{Evidence of past infection in plasma donors and antibody detection assays' performance Most convalescent plasma donors showed serological evidence of past SARS-CoV-2 infection, with 379 sam- ples reactive in the virus lysate assay ( $86.9 \%)$, and 346 showing detectable IgG antibodies in the Euroimmun assay (79.4\%) (Table). A total of 331 samples had detectable neutralising antibodies (75.9\%).}

sensitivity of immunoassays was determined based on donors with a previous laboratory-confirmed SARSCoV-2 infection, all sampled at least 30 days after diagnosis $(n=256)$. SARS-CoV-2 antibodies were detected in $254 / 256$ donors by virus lysate assay (sensitivity of $99.2 \%$ ) and in $232 / 256$ by Euroimmun (90.6\%) (Table). Each assay showed a decrease in detection rates over time elapsed from diagnosis. Neutralising antibodies were detected in $226 / 256$ donors (88.2\%), from which eight were notably negative by Euroimmun assay.

These findings confirm that most individuals with symptomatic SARS-CoV-2 infection develop measurable antibody responses, although the sensitivity of the assays evaluated is variable. The native virus ELISA assay format has been previously used for Middle East respiratory syndrome coronavirus (MERS-CoV) detection and shown to have a similar sensitivity, likely due to the presence of multiple viral antigens derived from infected cell cultures [15]. The low sensitivity of Euroimmun assay used here is in keeping with a recently reported sensitivity rate of $70.7 \%$ [16], albeit based on low sample numbers and with only $10 \%$ tested (6/62) after 30 days of disease onset.

\section{Host factors and neutralising antibody levels in plasma}

Neutralising antibody levels varied, with geometric mean titre (GMT) 1:333 (range<1:10-1:2,560). Titres of 1:100 or higher, aimed for clinical use, were measured in $34 \%$ of donations $(147 / 436)$. The highest levels of neutralising antibodies were found in donors hospitalised with laboratory-confirmed SARS-CoV-2 infection (data not shown, $\mathrm{n}=22$ ), those who were older (Figure $1 \mathrm{~A})$ and those who donated $<60$ days from diagnosis (Figure $1 \mathrm{C}$ ). Consistent with the lower detection rates, there was evidence for a significant decline in neutralising antibody levels over time. Median neutralising antibody titre significantly decreased from 1:70 in those donating within 40 days from diagnosis to $1: 43$ and 1:22 in those donating at least 50 days (Kruskal-Wallis test; 
Neutralising antibody titres and serological reactivity in Euroimmun IgG ELISA of plasma samples from donors recovered from COVID-19, relative to $(A, B)$ the age of donors and $(C, D)$ the time of diagnosis $(n=436$ plasma samples)

A.

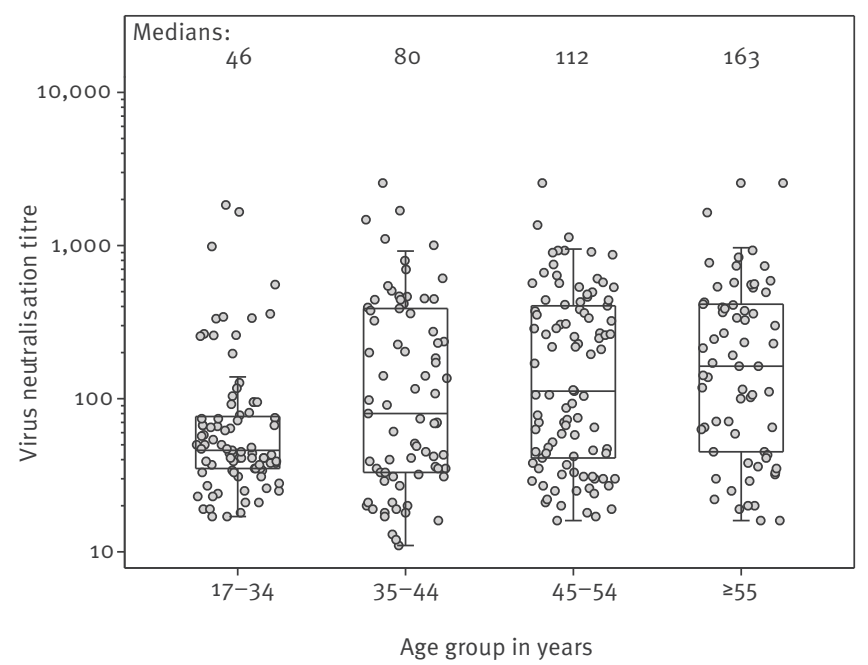

C.

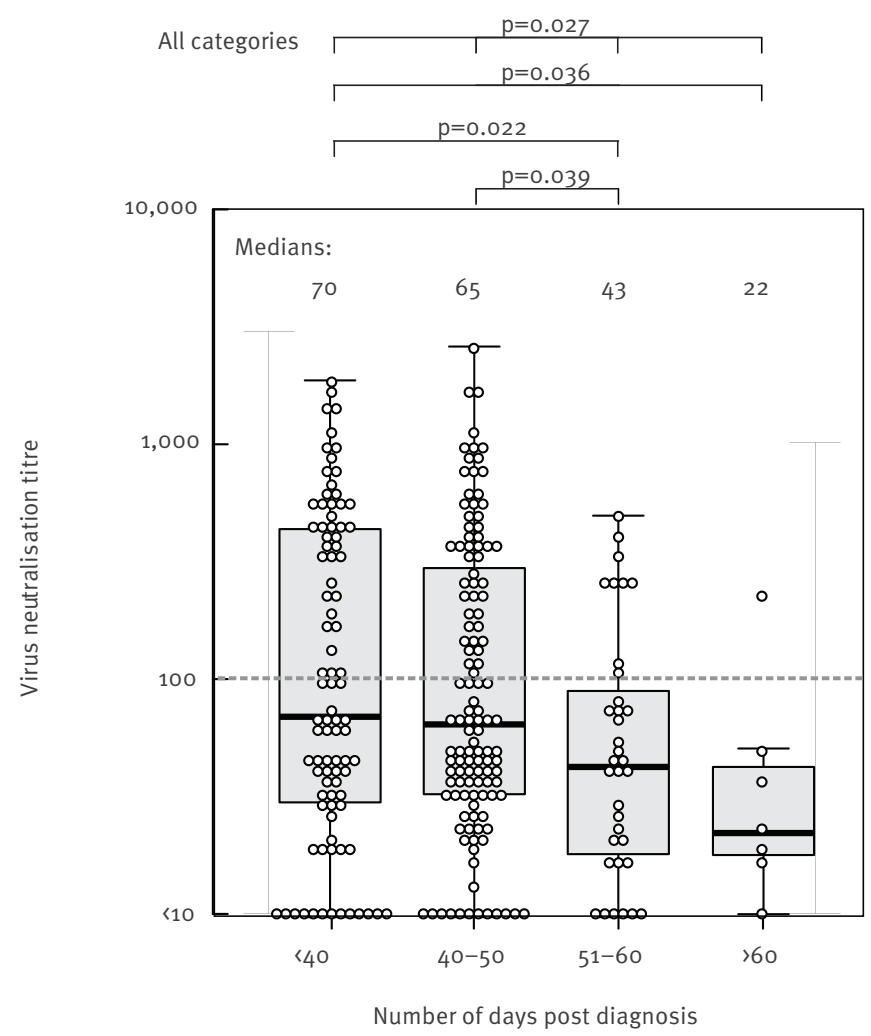

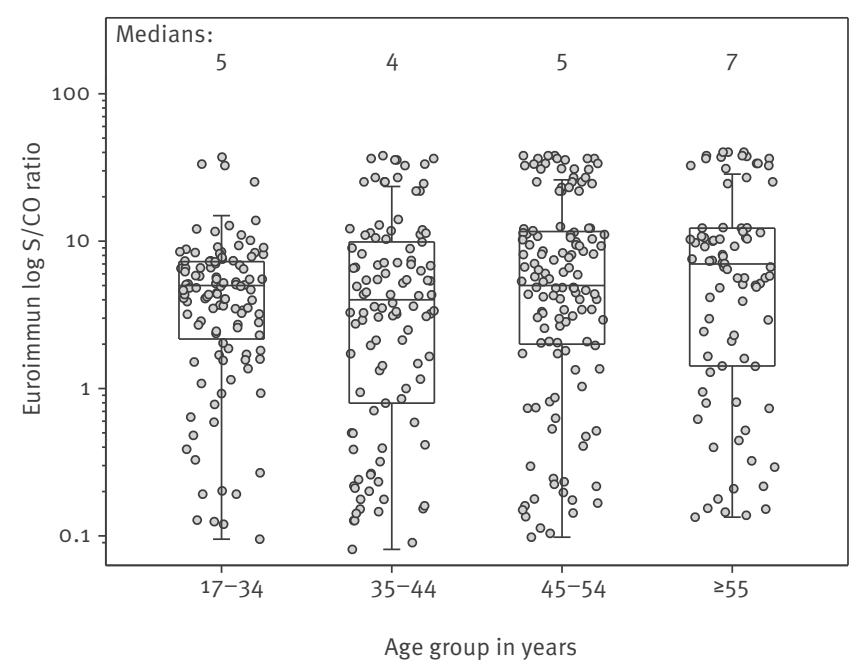

D.

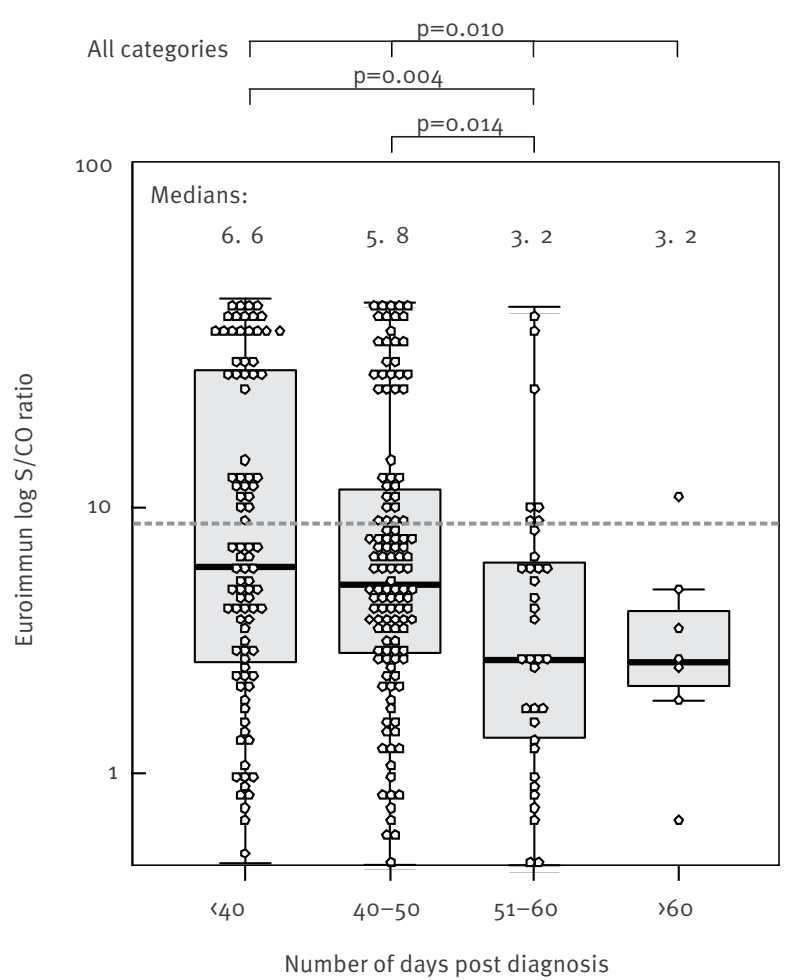

COVID-19: coronavirus disease; S/CO: signal to cut-off ratio.

A significant decline in virus neutralisation titre $(p=0.027)$ and Euroimmun reactivity $(p=0.010)$ was observed over time by Kruskal-Wallis test. 


\section{FIGURE 2}

(A) Virus neutralising antibody titres and (B) reactivity in Euroimmun assay, for plasma samples from donors recovered from confirmed or suspected COVID-19 $(n=436$ plasma samples)

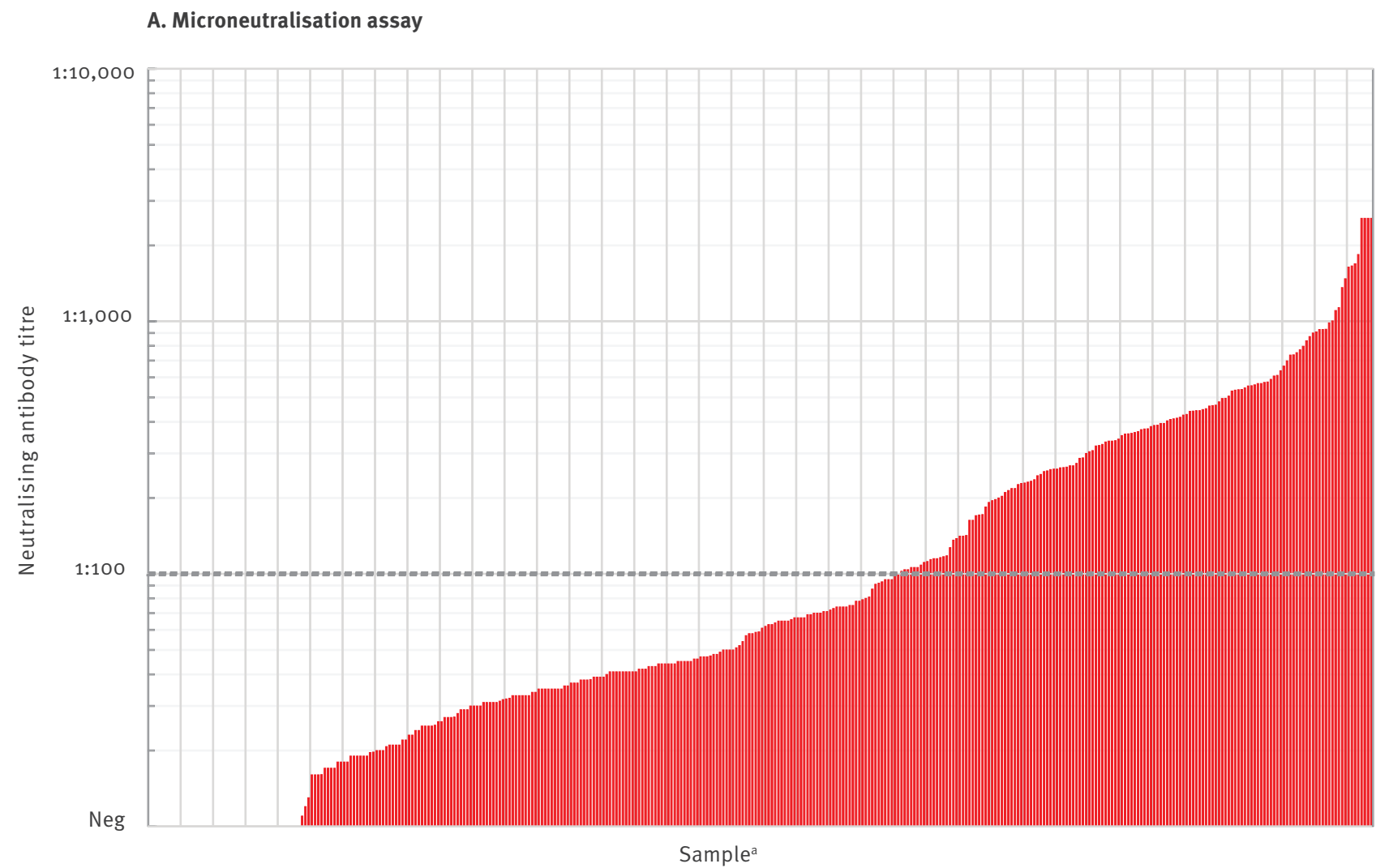

\section{B. Euroimmun EIA}

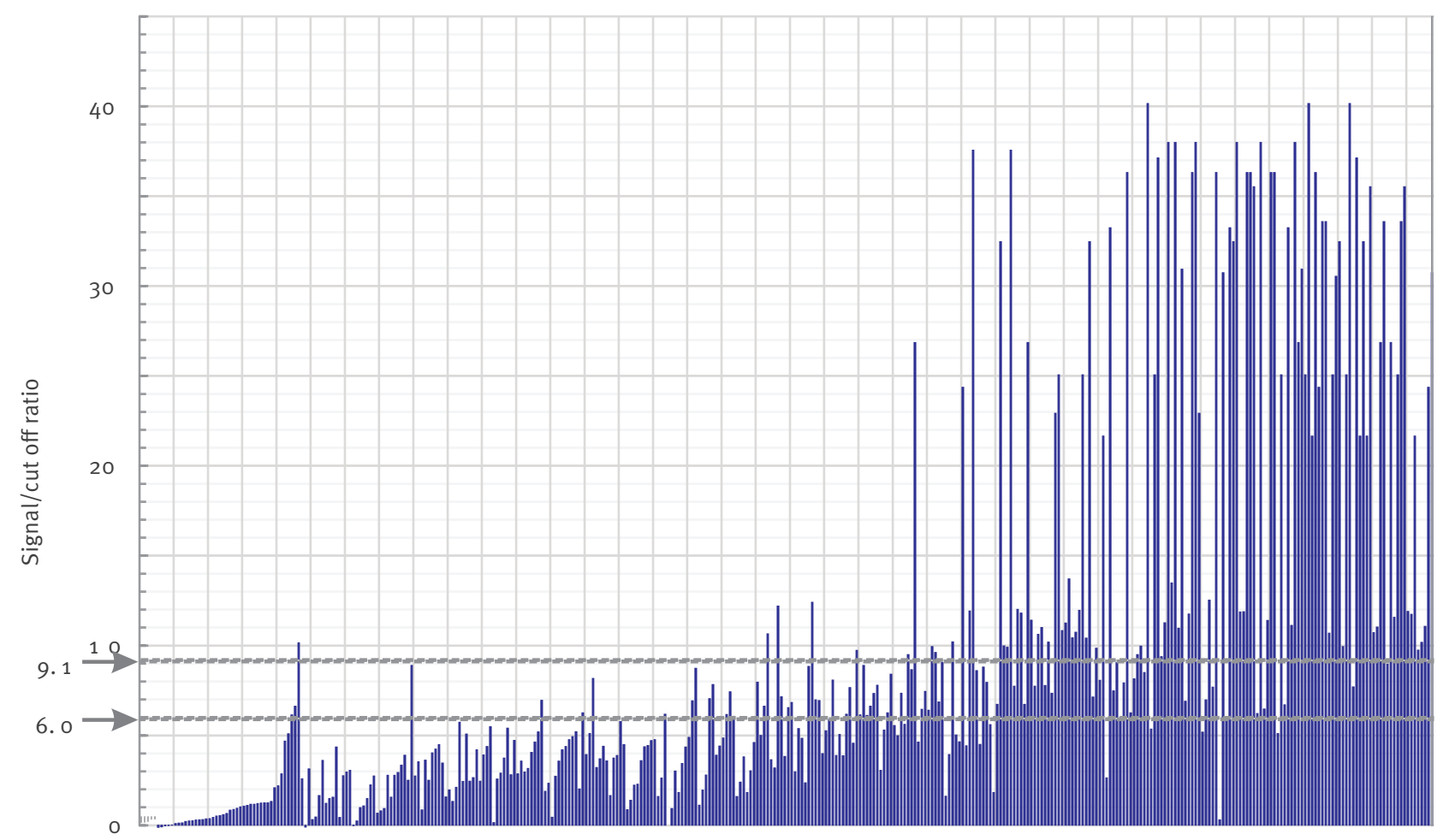

Sample

COVID-19: coronavirus disease; EIA: enzyme immunoassay; neg: negative.

a In all graphs, samples were ordered by virus neutralising antibody titres.

Comparison of neutralising antibody titres of the 436 convalescent plasma donor samples with reactivity in Euroimmun assay. Dotted lines show thresholds for therapeutic use in the neutralisation antibody assay (1:100) and Euroimmun assays (9.1 and 6.0). 
(A) Correlations between virus neutralising antibody titres and reactivities in Euroimmun ELISAs for plasma samples from donors recovered from confirmed or suspected COVID-19 and (B) receiver operating characteristic (ROC) analysis $(n=436$ plasma samples)

A.

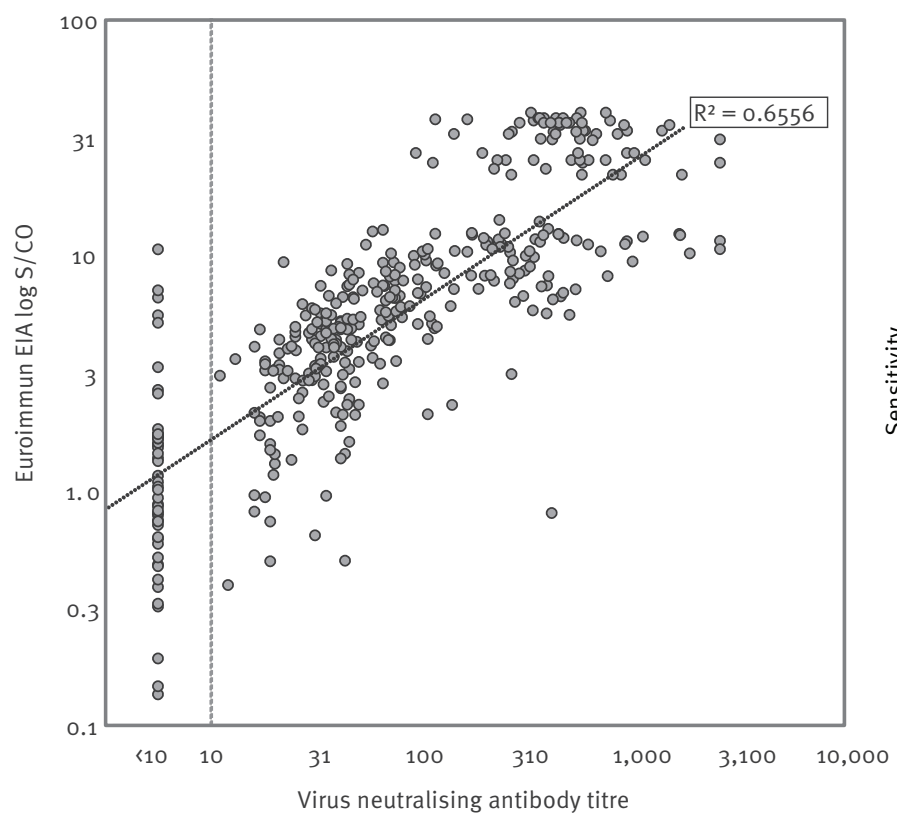

B.

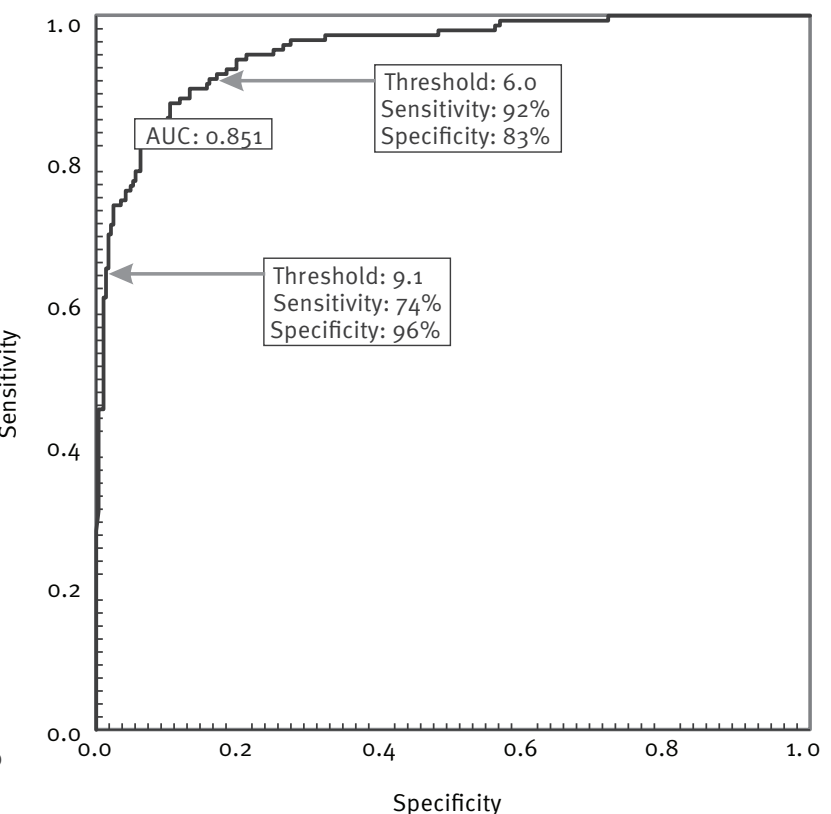

COVID-19: coronavirus disease; EIA: enzyme immunoassay; ROC: receiver operating characteristic; S/CO: signal to cut-off ratio; AUC: the area under curve.

A. Scatter plots of neutralising antibody titres of test samples with reactivities in Euroimmun assay. A line of best fit was estimated by linear regression using log-transformed values for the virus neutralising antibody and Euroimmun assays ( $p=2 \times 10-67)$.

B. ROC analysis of serology assays predicting virus neutralising antibody titres of $\geq 1: 100(n=436)$.

$\mathrm{p}=0.022$ ) or 6o days (Kruskal-Wallis test; $\mathrm{p}=0.027$ ) from diagnosis (Figure $1 \mathrm{C}$ ). Similar findings were previously demonstrated in other studies on convalescent plasma donors where the proportion of high titre donors (antibody level 1:512 or above) decreased from $52 \%$ on days $31-40$ post symptom onset to $28 \%$ on days 41-53 [12], and decreasing neutralising antibody levels have also been noted in SARS-CoV-2 infected hospitalised patients [17].

Similar to the neutralising antibody titres, a decrease was observed in Euroimmun S/CO by age (Figure 1B) and as time post diagnosis increased (Figure 1D), the latter being significant by Kruskal-Wallis test $(p=0.010)$.

\section{Predicting samples potentially suitable for convalescent plasma therapy using binding antibody titres}

Antibody reactivities in Euroimmun assay showed associations with neutralising antibody titres (Figure $2,3)$ and were strongly predictive of neutralising antibody titres by linear regression using log transformed values $\left(R^{2}=0.6556\right.$, $p<0.0001$; Figure $\left.3 A\right)$. By receiver operating characteristic (ROC) analysis, we investigated the sensitivity and specificity of the Euroimmun IgG assay for prediction of neutralising antibody titres of $1: 100$ or greater (Figure $3 \mathrm{~B}$ ). Lowering the currently used cut-off value of 9.1 to 6.0 would increase the number of high titre donations identified from $74 \%$ to $92 \%$ but would also reduce specificity, with false identification of units below the 1:100 threshold increasing from $4 \%$ to $17 \%$. This would translate to the marginal reduction of the median neutralisation titre from 1:375 ( $90^{\text {th }}$ percentile: $1: 65$ to $1: 1,658$ ) to $1: 261$ ( $90^{\text {th }}$ percentile: $1: 39$ to $1: 1,133)$. Based on these calculations, and in the absence of scalable neutralisation antibody test, we are now accepting all convalescent plasma donations with a minimum cut-off ratio of 6.0 in the Euroimmun assay for clinical use.

\section{Conclusions}

The study findings support the prioritisation of donation collection from only those with a laboratory-confirmed SARS-CoV-2 infection. In the study sample of 436 donations, 57 samples (13\%) were negative in all three serological assays. Evidence of a laboratory-confirmed SARS-CoV-2 infection was found only for two 
of these seronegative donors, compared with 254 in the 379 seropositive donations (67\%). With regard to the two initial laboratory-confirmed infections, subsequently testing negative by serological assay, we recognise that individuals with very mild infections may fail to develop a measurable immunoresponse. For the 55 seronegative donors with self-reported, non-priorlaboratory-confirmed COVID-19, it is also possible that they simply did not have SARS-CoV-2 infection, given the lack of specificity of diagnosis based on symptoms only. Given the currently limited sensitivity and specificity of antibody tests for SARS-CoV-2 by conventional diagnostic standards [16-20], reporting of results to such donors needs to be undertaken very carefully and the test limitations explained.

In conclusion, most individuals with previously laboratory-diagnosed SARS-CoV-2 infection develop measurable antibody responses and also develop neutralising antibodies. A self-diagnosed infection is not a desirable selection criterion for convalescent plasma donors. Neutralising antibody levels declined within the first 3 months following diagnosis, which suggests the collection of convalescent plasma with high neutralising antibody may be optimum within a short time window. Finally, the study indicates that commercial ELISA can perform effectively as surrogate assays for predicting neutralising antibody titres and represent a streamlined and rapid way to guide convalescent plasma donor selection.

NHS Blood and Transplant Convalescent Plasma Testing Group

Stephen Thomas, Sheila MacLennan, Lise Estcourt, Su Brailsford, Hatice Baklan, Kate Tettmar, Jeremy Kellington, Joanne Sell, Gail Miflin.

\section{*Authors' correction}

A statement regarding funding was added to the acknowledgements' section on 25 March 2021.

\section{Acknowledgements}

We would like to thank all the donors who have kindly donated convalescent plasma. We are grateful for everybody within NHS Blood and Transplant who have contributed in the Convalescent Plasma programme across the donor outreach, collection, transporting, processing and issue of convalescent plasma and the staff of NHSBT Clinical Trials Unit. We would also like to thank the staff members of the Virus Reference Division at Public Health England Colindale.

Funding*: This work was funded by the Department of Health and Social Care (DHSC)/UKRI/NIHR COVID-19 Rapid Response Grant (COV19-RECPLA).

\section{Conflict of interest}

None declared.
Authors' contributions

H. Harvala coordinated the experiments, analysed the data and wrote the first draft of manuscript; J. Mehew, M. Robb, R. Johnson and P. Simmonds performed the statistical analysis and constructed figures; M. Patel and R. Gopal performed the experiments; S. ljaz, S. Dicks, N. Watkins, M. Zambon and T. Brooks coordinated the samples and testing; D. Roberts, $R$. Gopal, N. Watkins, P. Simmonds and M. Zambon critically revised the final version. All NHSBT authors coordinated to the convalescent plasma collections and subsequent testing. All authors approved the final version of the paper.

\section{References}

1. World Health Organization (WHO). Coronavirus disease (COVID-19) pandemic. [Accessed 10 Jun 2020]. Geneva: WHO. Available from: https://www.who.int/emergencies/diseases/ novel-coronavirus-2019

2. Coronaviridae Study Group of the International Committee on Taxonomy of Viruses. The species Severe acute respiratory syndrome-related coronavirus: classifying 2019-nCoV and naming it SARS-CoV-2. Nat Microbiol. 2020;5(4):536-44. https://doi.org/10.1038/s41564-020-0695-Z PMID: 32123347

3. An EU programme of COVID-19 convalescent plasma collection and transfusion Guidance on collection, testing, processing, storage, distribution and monitored use. [Accessed 12 Jun 2020]. Available from: https://ec.europa. eu/health/sites/health/files/blood_tissues_organs/docs/ guidance_plasma_covid19_en.pdf

4. Recommendations for Investigations COVID-19 Convalescent Plasma recommendation. 1 May 2020. [Accessed 12 Jun 2020]. Available from: https://www.fda.gov/vaccines-blood-biologics/ investigational-new-drug-ind-or-device-exemption-ideprocess-cber/recommendations-investigational-covid-19convalescent-plasma

5. Duan K, Liu B, Li C, Zhang H, Yu T, Qu J, et al. Effectiveness of convalescent plasma therapy in severe COVID-19 patients. Proc Natl Acad Sci USA. 2020;117(17):9490-6. https://doi. org/10.1073/pnas.2004168117 PMID: 32253318

6. Shen C, Wang Z, Zhao F, Yang Y, Li J, Yuan J, et al. Treatment of 5 Critically Ill Patients With COVID-19 With Convalescent Plasma. JAMA. 2020;323(16):1582-9. https://doi.org/10.1001/ jama.2020.4783 PMID: 32219428

7. Rojas M, Rodríguez Y, Monsalve DM, Acosta-Ampudia Y, Camacho B, Gallo JE, et al. Convalescent plasma in Covid-19: Possible mechanisms of action. Autoimmun Rev. 2020;19(7):102554. https://doi.org/10.1016/j. autrev.2020.102554 PMID: 32380316

8. Long QX, Liu BZ, Deng HJ, Wu GC, Deng K, Chen YK, et al. Antibody responses to SARS-CoV-2 in patients with COVID-19. Nat Med. 2020;26(6):845-8. https://doi.org/10.1038/s41591020-0897-1 PMID: 32350462

9. Guo L, Ren L, Yang S, Xiao M, Chang D, Yang F, et al. Profiling Early Humoral Response to Diagnose Novel Coronavirus Disease (COVID-19). Clin Infect Dis. 2020;ciaa310. https://doi. org/10.1093/cid/ciaa310 PMID: 32198501

10. Zhao J, Yuan Q, Wang H, Liu W, Liao X, Su Y, et al. Antibody responses to SARS-CoV-2 in patients of novel coronavirus disease 2019. Clin Infect Dis. 2020; ciaa344. https://doi. org/10.1093/cid/ciaa344 PMID: 32221519

11. Wu F, Wang A, Liu M, Wang Q, Chen J, Xia S, et al. Neutralizing antibody responses to SARS-CoV-2 in a COVID-19 recovered patient cohort and their implications. MedRxiv. 2020. Available from: https://www.medrxiv.org/content/10.1101/2020.03.30.2 0047365v1.full.pdf

12. Wang X, Guo X, Xin Q, Pan Y, Li j, Chu Y, et al. Neutralising antibody responses to SARS-CoV-2 in COVID-19 inpatients and convalescent patients. MedRxiv. 2020. Available from: https:// www.medrxiv.org/content/10.1101/2020.04.15.20065623V3

13. Harvala H, Robb M, Watkins N, Ljaz S, Dicks S, Patel M, et al. Convalescent plasma therapy for the treatment of patients with COVID-19: Assessment of methods available for antibody detection and their correlation with neutralising antibody levels. MedRxiv. 2020. Available from: https://www.medrxiv. org/content/10.1101/2020.05.20.20091694V1

14. Roberts DJ, Miflin G, Estcourt L. Convalescent plasma for COVID-19: Back to the future. Transfus Med. 2020;30(3):174-6. https://doi.org/10.1111/tme.12700 PMID: 32447783

15. Agnihothram S, Gopal R, Yount BL Jr, Donaldson EF, Menachery VD, Graham RL, et al. Evaluation of serologic and antigenic relationships between middle eastern respiratory syndrome coronavirus and other coronaviruses to develop vaccine 
platforms for the rapid response to emerging coronaviruses. J Infect Dis. 2014;209(7):995-1006. https://doi.org/10.1093/ infdis/jit609 PMID: 24253287

16. Jääskeläinen AJ, Kekäläinen E, Kallio-Kokko H, Mannonen L, Kortela E, Vapalahti O, et al. Evaluation of commercial and automated SARS-CoV-2 IgG and IgA ELISAs using coronavirus disease (COVID-19) patient samples. Euro Surveill. 2020;25(18):2000603. https://doi.org/10.2807/1560-7917. ES.2020.25.18.2000603 PMID: 32400364

17. Brochot E, Demey B, Touze A, Belouzard S, Dubuisson J, Schmit JL, et al. Anti-spike, anti-nucleocapsid and neutralising antibodies in SARS-CoV-2 inpatients and asymptomatic carriers. MedRxiv. 2020. Available from: https://www.medrxiv. org/content/10.1101/2020.05.12.20098236v2

18. Lassaunière $R$, Frische $A$, Harboe $Z B$, Nielsen $A C Y$, Fomsgaard $A$, Krogfelt KA, et al. Evaluation of nine commercial SARSCoV-2 immunoassays. MedRxiv. 2020. Available from: https:// www.medrxiv.org/content/10.1101/2020.04.09.20056325V1

19. Caini S, Bellerba F, Corso F, Díaz-Basabe A, Natoli G, Paget J, et al. Meta-analysis of diagnostic performance of serological tests for SARS-CoV-2 antibodies up to 25 April 2020 and public health implications. Euro Surveill. 2020;25(23):2000980. https://doi.org/10.2807/1560-7917.ES.2020.25.23.2000980 PMID: 32553061

20. Okba NMA, Müller MA, Li W, Wang C, GeurtsvanKessel

$\mathrm{CH}$, Corman VM, et al. Severe Acute Respiratory Syndrome Coronavirus 2-Specific Antibody Responses in Coronavirus Disease Patients. Emerg Infect Dis. 2020;26(7):1478-88. https://doi.org/10.3201/eid2607.200841 PMID: 32267220

\section{License, supplementary material and copyright}

This is an open-access article distributed under the terms of the Creative Commons Attribution (CC BY 4.0) Licence. You may share and adapt the material, but must give appropriate credit to the source, provide a link to the licence and indicate if changes were made.

Any supplementary material referenced in the article can be found in the online version.

This article is copyright of the authors or their affiliated institutions, 2020. 